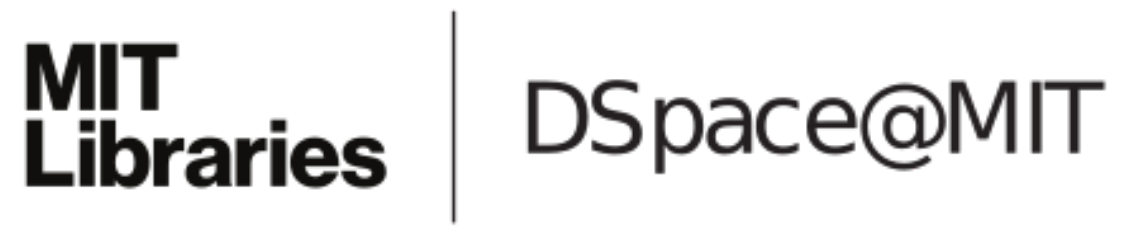

\author{
MIT Open Access Articles
}

Optimization of time-based rates in forward energy markets

The MIT Faculty has made this article openly available. Please share how this access benefits you. Your story matters.

Citation: Wang, J., S. Kennedy, and J. Kirtley. "Optimization of Time-Based Rates in Forward Energy Markets." 7th International Conference on the European Energy Market 2010 (EEM). 1-7. (C) Copyright 2010 IEEE

As Published: http://dx.doi.org/10.1109/EEM.2010.5558713

Publisher: Institute of Electrical and Electronics Engineers (IEEE)

Persistent URL: http://hdl.handle.net/1721.1/72552

Version: Final published version: final published article, as it appeared in a journal, conference proceedings, or other formally published context

Terms of Use: Article is made available in accordance with the publisher's policy and may be subject to US copyright law. Please refer to the publisher's site for terms of use. 


\title{
Optimization of Time-Based Rates in Forward Energy Markets
}

\author{
J. Wang, Student Member, IEEE, S. Kennedy, Member, IEEE, and J. Kirtley, Fellow, IEEE
}

\begin{abstract}
This paper presents a new two-step design approach of Time-Based Rate (TBR) programs for markets with a high penetration of variable energy sources such as wind power. First, an optimal market time horizon must be determined that balances between production generation forecast accuracy and customers' scheduling flexibility, in order to achieve a minimum system cost in forward and real-time reserve energy markets. The time horizon obtained is used as a known parameter in the subsequent design of TBR's pricing values. Customers' scheduling strategies modeled by price elasticity matrices along with current system conditions are considered in the price calculation process, during which system cost of the forward energy market is minimized.
\end{abstract}

Index Terms - time-based rates, wind power prediction error, forward energy markets, real-time reserve markets, load shifting flexibility, price elasticity matrix, system cost minimization

\section{INTRODUCTION}

$\mathrm{I}_{\mathrm{n}}^{\mathrm{n}}$ $\mathrm{n}$ the past several decades, with the development of smart metering and control technologies, Time-Based Rates (TBR) programs have been applied to modern power systems to increase competition, reduce market power, improve reliability, and in particular, to enable the use of cleaner renewable energy technologies [1]-[4]. FERC's reports [3] defines the TBR programs as one of the two major categories of demand response programs, which incentivize customers to schedule their loads by time-varying price signals and thus to promote more efficient markets. A range of TBR programs are currently offered directly to retail customers, for instance, real-time pricing, time-of-use and critical-peak pricing.

Although the emergence of TBR brings about more flexibility and options for both the supply and demand side, it also increases the uncertainties in power system planning and operation. At the same time, factors such as change of system marginal cost and electricity demand, which can be caused the wind power prediction inaccuracies or temperature, makes it

This work was supported in part by the Masdar Institute of Science and Technology.

J. Wang is with the Massachusetts Institute of Technology, Cambridge, MA 02139 USA (phone: +1 617258 8494; fax: 617-258-6774; e-mail: jkwang@mit.edu).

$\mathrm{S}$. Kennedy is with the Masdar Institute of Science and Technology, Abu Dhabi, UAE (phone: +971 2698 8030; fax: +971 2698 8121; e-mail: skennedy@mist.ac.ae).

J. Kirtley is with the Massachusetts Institute of Technology, Cambridge, MA 02139 USA (phone: +1 617253 23574; e-mail: kirtley@mit.edu). difficult for TBR programs to induce their desired load profile and market efficiency [4]-[6].

Therefore, in order for TBR programs to result in increased market efficiency, and not simply create additional uncertainties, it is important to create a time-based rate design that provides customers with sufficient time and flexibility to schedule their load in advance while setting prices and dispatch schedules that accurately reflect the eventual system conditions at the time of the load [3].

Two critical factors of TBR programs' design are the pricing value and the time horizon over which prices are specified and customers can view in advance (e.g., 24 hours of the following day in a hourly day-ahead market). Many of the existing design approaches only qualitatively describe the process to set up a TBR program without specifying a quantitative method to optimize the two factors for a given power system [3], [7] and [8]. Some works propose a TBR pricing procedure based on the empirical data of system conditions. Other works calculate prices, requiring the knowledge of numerous system components' physical parameters (e.g. ramp-up and ramp-down limits, capacity, total energy generation/consumption within a certain time horizon). Limits are obvious for these approaches. Current system conditions and active demand response are not considered when setting the prices, and building physical models of every system component is an overwhelming task. In addition, the TBR time horizon, which influences the customers' scheduling flexibility and the system conditions' prediction accuracy in forward energy markets, is ignored in most of the revised works [4], [9].

To solve these problems, a new design approach of TBR programs is proposed in this paper. It first optimizes the TBR time horizon considering competing interests from the perspective of wind power prediction and customer scheduling flexibility in order to achieve a minimum system cost in forward and real-time reserve supplement energy market. The time horizon obtained is used as a known parameter in the subsequent design of TBR pricing values. Customers' scheduling strategies modeled by price elasticity matrices along with current system conditions are considered in the price-setting process, during which system cost of the forward energy market is minimized.

The TBR time dimension discussed in this paper is one hour. Namely, the system cost functions are built considering generators and retailers bid their hourly energy production and consumption in forward energy markets. However, the application of the proposed TBR design approach is not limited to hourly pricing design. More extensive applications 
can be obtained by using a different time dimension following the same approach.

Section II describes the proposed TBR design approach in a general way. Section III develops the system cost function based on which the TBR's time horizon is optimized. Section IV presents the TBR's price setting process. Section V presents the conclusion of this study.

\section{DESIGN APPROACH FOR TIME-BASED RATES}

For all Time-Based Rates (TBR) programs, two common critical factors are the time horizon and pricing. The time horizon of time-based rates decides how much information that customers are exposed to, and the pricing decides what market signals to release to customers, which in turn influences their consumption. Moreover, once the time horizon is decided for a certain TBR program, it should remain fixed. In other words, it is not practical for customers to see price updates every 12 hours today but every 4 hours tomorrow. In contrast, the price values in a TBR program are time-varying by definition, and should be set according to systems conditions and economics as discovered by the current forward energy markets [1], [3] and [10]. Therefore, we propose a two-step design approach to optimize the TBR program under given power system and market conditions:

1. Optimize the time horizon of the time-based rates under a system cost function, which is modeled based on the empirical and future estimation of the power system's conditions and economics.

2. Decide the TBR prices over the obtained optimal time horizon with the currently available system and market conditions.

Therefore, for a given power system, the TBR program's time horizon is optimized and fixed for long-term operation, whereas prices are routinely optimized under the short-term conditions.

Other factors may be also involved in the time-based rates design. Factors such as the time dimension of pricing variation (e.g. price changes every 5 minutes or every 15 minutes), which depend on the specific TBR programs and factors such as metering capabilities and customer tolerance for price variability, are out of the scope of this paper.

\section{DECIDING TIME HoRIZON OF TIME-BASED RATES}

\section{A. System Cost Function of the Wind Prediction Error}

The wind prediction time horizon influences the Wind Power (WP) prediction accuracy, which in turn affects the system cost. [11] proposes a model assessing the WP prediction error cost in an hour-ahead market. In this paper, we generalize the model in [11] by making it independent of specific WP prediction values and applicable to forward energy markets over a long time horizon. The system cost's dependency on the TBR program's time horizon is also shown in our proposed model.

First, we model the PDF of wind prediction error, which depends on prediction time horizon. For any statistical model, its PDF can be estimated given the mean $(\mu)$ and standard deviation $(\sigma)$, which in this context will be defined as:

$$
\begin{aligned}
& \mu=\frac{1}{N} \sum_{n}^{N} \frac{\left(p_{p r d, n}-p_{m s, n}\right)}{p_{\text {ins }}}=\frac{1}{N} \sum_{n}^{N} e_{n} \\
& \sigma=\sqrt{\frac{1}{N} \sum_{n}^{N}\left(e_{n}-\mu\right)^{2}}
\end{aligned}
$$

where $N$ is the number of measurements, $p_{p r d, n}$ is the predicted power for the time period $n, p_{m s, n}$ is the actual power value measured in the same period, $p_{\text {ins }}$ is the installed $\mathrm{WP}$, and $e_{n}$ is the normalized WP prediction error (for the same period). In this paper, the time period is one hour, and predicted and measured values correspond to WP energy production at that hour. Many of wind prediction models are built with the condition of $\mu$ equals to 0 [12]-[14], and others state that the absolute value of $\mu$ can be presented as a function of prediction time horizon [11], [15].

In general, the $\sigma$ depends on the specific type of WP prediction model and parameters related to forecast conditions, wind turbines' physical variables and installations' local conditions. Previous works show that among all these factors, that a parameter that commonly affects the WP prediction $\sigma$ and can be optimized during the TBR program design is the forecast time horizon. For instance, in [16] and [17], it was proved that, for forecasts up to 48 hours, $\sigma$ was a function of the normalized prediction power, the forecasted horizon, and the size of the region where the wind farm installations are located. [12] uses a wind-power model to characterize the prediction uncertainty in WP generation. Error prediction $\sigma$ increase with the prediction time horizon from 1 to 48 hours. In [18], an ARMA time-series prediction method is proposed to predict WP energy from 1 to 6 hours ahead. Prediction errors are compared for different seasonal periods and different prediction time horizons. Fig. 1 shows the dependency of $\sigma$ on prediction time horizon, found in [16] and [17].

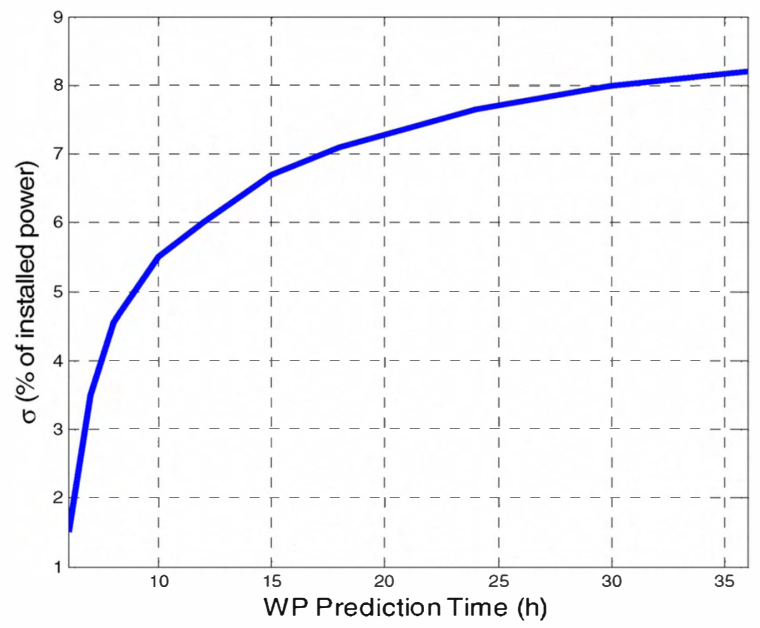

Fig. 1. Standard deviation of WP prediction error as an increasing function of prediction time horizon. 
[19] shows that independently of the prediction method used for WP prediction, errors practiced in previous WP forecasts for different time horizon (1 hour ahead, 2 hour ahead and so on) can be collected. With these values, an error distribution curve for each time horizon can be obtained. By a simplified approach in [19], from the error distribution curve and the predicted WP, $\sigma$ for each time period can be estimated assuming a certain probability distribution and thus formulated as a function of prediction time horizon. Therefore,

$\sigma=\sigma(t)$

where $t$ is the WP forecast time horizon.

In the next step, based on the revised works [12]-[15] and [18], we assume a normal distribution function to represent the PDF of the prediction error. The PDF is function of the TBR program's time horizon with the standard deviation defined by (3), shown as:

$f(e, t)=\frac{1}{\sqrt{2 \pi \sigma(t)^{2}}} e^{-\frac{(e-\mu(t))^{2}}{2 \sigma(t)^{2}}}$

Equation (4) enables us to model the system cost in a general case regardless of the specific WP prediction values.

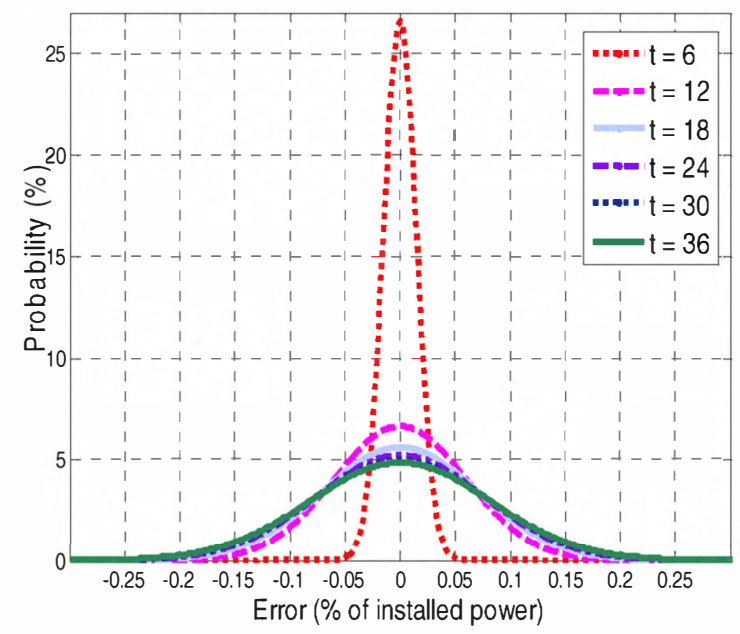

Fig. 2. PDF of WP prediction error with varying prediction time horizons. The PDF is described by (4), with $\sigma$ sampled in Fig. 1 . and $\mu$ set as 0 .

For illustration purposes, in Fig. 2, different normal distribution functions have been represented corresponding to different values of prediction time horizons from Fig. 1.

With the PDF of WP prediction error, the Total Probabilistic Prediction Error (TPPE) can be calculated as the expected value, upward $\left(T P P E_{u}\right)$ and downward $\left(T P P E_{d}\right)$ as the follows:

$T P P E_{u}(t)=\int_{e=0}^{e=+\infty} e \cdot f(e, t) \cdot p_{\text {ins }} \cdot d e$

and

$T P P E_{d}(t)=\int_{e=-\infty}^{e=0} e \cdot f(e, t) \cdot p_{\text {ins }} \cdot d e$
For a symmetric distribution, the two expected values are equal, although in general, an asymmetric distribution could also be used whereby the two values would be different. [11], [20]-[22] show that the total prediction error cost of the power system can be calculated as the balancing cost in real-time supplemental reserve energy market. We revise the system cost assessment equation presented in [11] and make it as a function of the TBR program's time horizon $T$ as:

$$
\begin{aligned}
& y_{r s v, t_{0}}(T)= \\
& \quad-\sum_{t=t_{0}}^{T+t_{0}}\left\{T P P E_{u}(t) \cdot E P d_{t}+T P P E_{d}(t) \cdot E P u_{t}\right\}
\end{aligned}
$$

where $t_{0}$ is the starting time of $T, E P u_{t}$ is the supplemental-up reserve energy in hour $t$, and $E P d_{t}$ is the supplemental-down reserve energy price in hour $t$.
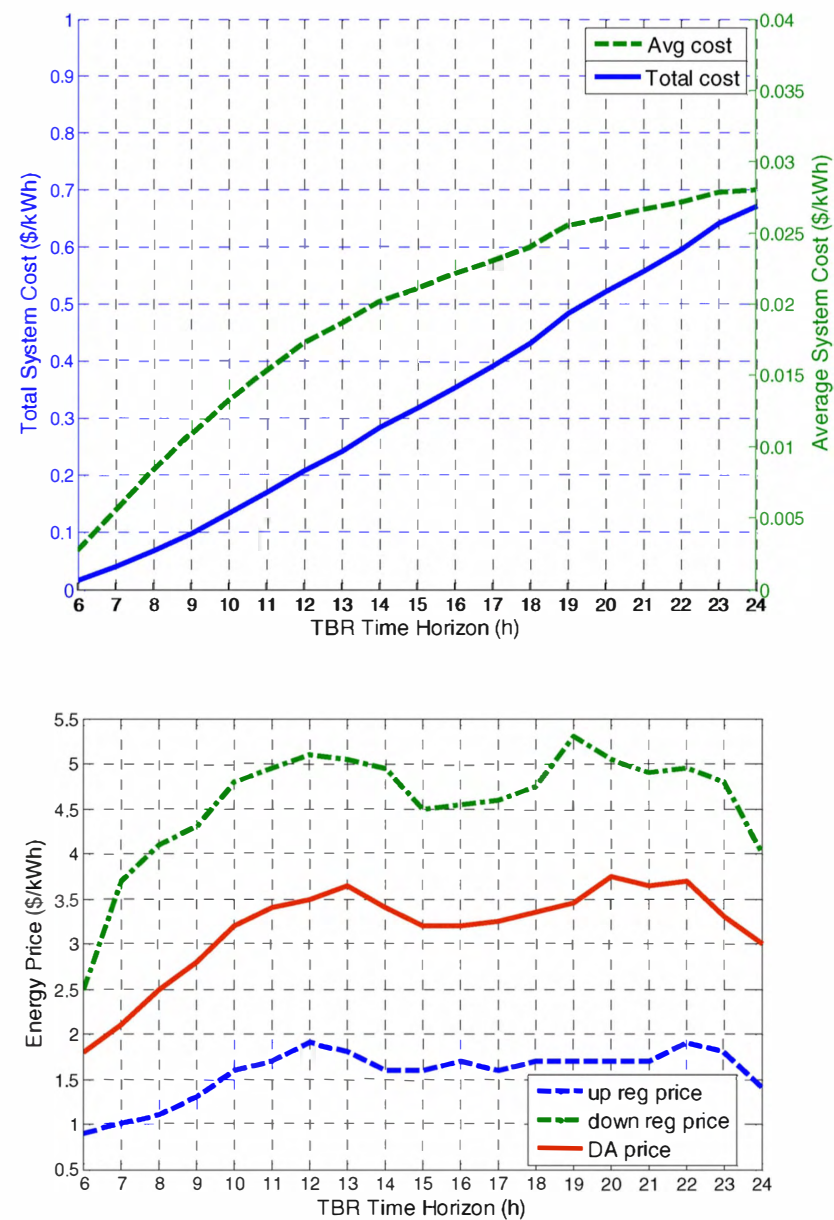

Fig. 3. System cost function of TBR's time horizon (top) and the energy market prices (bottom). The top figure presents, for installed wind power equals to $1 \mathrm{kWh}$, the total system cost calculated by (7) and the value averaged over the TBR's time horizon $T$. WP prediction deviation is modeled by PDF shown in Fig. 2. and the reserve market prices are collected from [11] shown in the bottom figure.

In order to use (7) to estimate the system cost caused by WP prediction error, three assumptions are made here:

1. The WP prediction errors are balanced by using supplemental reserve energy. In practice, spinning reserve energy would be used to correct real-time 
generation errors, and then, supplemental reserve energy would be dispatched [20]-[22].

2. The prices $E P u_{t}$ and $E P d_{t}$ are decided separately and thus are independent of WP prediction time horizon $t[11]$.

3. Wind generators bid into the forward energy markets with the WP forecasted obtained in the least time ahead. In other words, they bid at the hour right before the market is closed in order to get the predicted WP as accurate as possible. Therefore, the WP prediction time horizon in (7) starts from $t=1$.

For illustration purposes, Fig. 3 shows the system cost induced from WP prediction error based on (7), and energy prices in DA and supplemental reserve market presented in [11]. Fig. 3 shows that both the total system cost and its average value per hour are increasing functions of WP prediction time horizon. This indicates that WP prediction horizon increases system costs due to not only the cumulating effect but also deteriorating forecast accuracy over time.

\section{B. System Cost Function of Customers' Scheduling Flexibility}

Two factors decide how customers' response to TBR programs influences the system cost: (1) customers' scheduling strategies and (2) customers' scheduling flexibility [1]-[3] and [27]. While the first factor depends on the load controlling algorithms and technologies available to customers, the second factor depends on the time horizons of the timevarying price that customers can view in advance.

Previous works provide various models of load scheduling that can be used to calculate system cost under a given timebased rate horizon. For instance, [23]-[25] propose sets of fuzzy logic rules based on which customers' loads can be scheduled. System costs are optimized together with customers' satisfaction, which is modeled by indoor lighting and temperature. [26] and [27] schedule loads with the knowledge of customers' inter-temporal shifting elasticities. Price elasticity matrices are modeled within a given TBR program's time horizon to find the price and load schedules for the minimum system cost. For industrial and commercial customers, [28]-[30] propose load scheduling algorithms that maximize the customers' profit under given energy prices within a given time horizon. Energy conservation conditions are held in these models. And the system costs induced can be estimated by the obtained load schedule and energy price with the known system conditions.

To model the influence of customers' scheduling flexibility on the system, denote the generation cost in the hourly forward energy market of a time horizon $T$ as:

$y_{q, t_{0}}(T)=\min \sum_{t=t_{0}}^{T+t_{0}} \sum_{j}^{J} C_{j}\left(P_{j, t}\right)$

s.t. $q(\cdot, T) \leq 0$

where (9) is the customers' load profile with the system conditions known within $T, t_{0}$ is the starting time of the time horizon period $T, y_{q, t_{0}}(T)$ is the minimum system cost obtained by applying (9) with a starting time at $t_{0} . C_{j}$ is the cost function of the generator at bus $j$, and $P_{j, t}$ is the output power of that generator at hour $t$.

The system cost function (8) is predicted as an increasing or function of the time-based rates horizon $T$, but we cannot draw the same conclusion for its average value per hour. This is because $T$ can be any period within any periodic electricity consumption timeframe (e.g. $2 \mathrm{pm}$ to $6 \mathrm{pm}$ in 24 hours, or 6 am to $12 \mathrm{pm}$ in 72 hours), and hourly system marginal costs are usually different within those timeframes. However, in general, the longer the time horizon over which customers can view time-based rates in advance, the more flexibility customers get to schedule loads, which in turn induces greater potential to reduce the system cost.

\section{Optimizing the Time-Based Rates' Horizon}

Given the cost functions of WP prediction error and customers' shifting flexibility shown as (7) and (8), the system cost function of TBR program's time horizon $T$ is proposed as:

$y_{\text {total }}(T)=\sum_{l=0}^{L}\left\{y_{q,(l \times T+1)}(T)+y_{r s v,(l \times T+1)}(T)\right\}$

and

$L=\left\lfloor\frac{t_{\max }}{T}\right\rfloor$

where $t_{\max }$ is the length of a given periodic electricity consumption timeframe (e.g. 24 hours as a daily load profile, 48 hours and so on), and (11) implements the floor function on $T$ 's number within this timeframe. Within the sum operator, the first item presents the generation cost in forward market dispatch with demand response modeled by (9), and the second item represents the cost in real-time reserve supplement energy market caused by WP prediction errors. The sum of the two items estimates the total cost induced in the energy markets that starts from hour $l \times T+1$. However, $T$ can be any period within any periodic electricity consumption timeframe (e.g. $2 \mathrm{pm}$ to $6 \mathrm{pm}$ in 24 hours, or 6 am to $12 \mathrm{pm}$ in 72 hours), and hourly system marginal costs in energy markets are usually different for those time horizon. Therefore, the total costs of $T$ are summed over $t_{\max }$ in order to make the normalized system marginal costs the same. For illustration purpose, Fig. 4 shows the development of (10) from (8) and (7).

In addition, the time horizon of a TBR program is should not be changed frequently once has been decided, because it is not practical to expose customers to a different time horizon every time. Therefore, the chosen TBR time horizon should be applicable to general system operation conditions in the long term. For this reason, the parameters of the system cost function should be estimated from the system's empirical data.

It is important to notice that (10) only reflects the partial system costs. In practice, the total system cost involves costs induced in multiple forward markets, real time markets of energy, ancillary services, transmission rights and so on [10]. [20] and [21]. The purpose of establishing (10) is to model the competing interests of minimizing WP prediction error and 
maximizing customers' scheduling flexibility from the perspective of an optimum TBR program time horizon. For this purpose, only costs in the short-term hourly forward and reserve supplement energy markets are involved in (10). This is justified by previous studies on WP prediction cost assessments and customers' scheduling models [11], [20]-[22]. Moreover, costs that are induced by other factors (such as solar power prediction) and are related to the setting of timebased rates' horizon may be added to (10) if necessary.

The optimal time horizon of time-based rates is found by optimizing (10) over $T \in\left(0, t_{\max }\right)$.

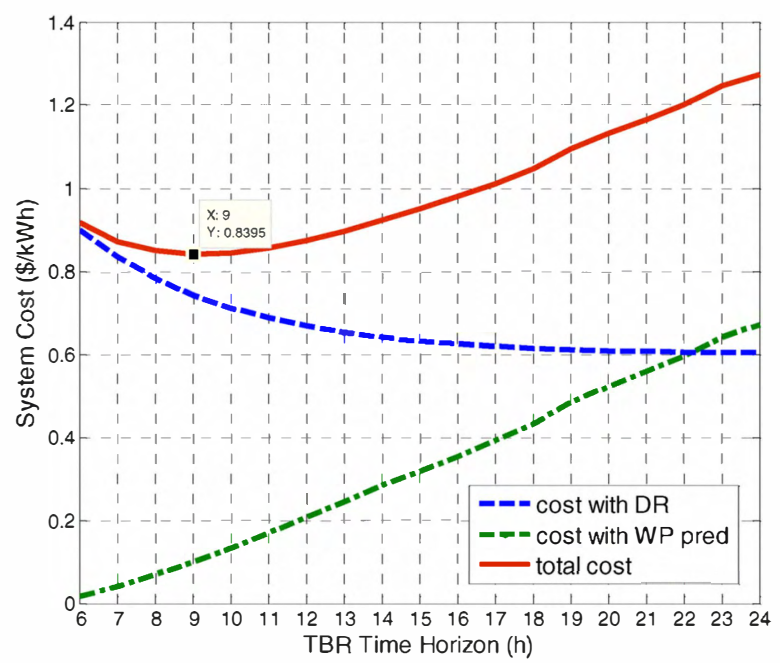

Fig. 4. System cost function of TBR's time horizon. The function shown assumes all loads are fully responsive. The costs are calculated by (10) and normalized by the installed WP. The function is developed from WP cost function shown (with the same data in Fig. 3) and cost function with customers' shifting calculated by (8) with (9) defined in [30]. The optimal TBR's time horizon found in the shown function is $T=9$.

\section{DECIDING PRICING OF TIME-BASED RATES}

Time-based rates' pricing plays the role of transforming the currently available system conditions into an economic signal to customers and thus achieves the goal of creating an efficient market. However, uncertainties that reduce market efficiency emerge under TBR programs in market operations. For example, when a forecasted real-time price is provided to end users in advance of their consumption, the final load amount may deviate from the forecasted value, leading to a real-time price that is inappropriate for the needed generation. Thus, system operators may find it harder to predict the future demand and to commit or dispatch the correct amount of generation when there is an active demand response.

Thus, it is critical to consider the current system conditions and demand response when deciding the TBR programs' price. [6] proposes a bidding mechanism that follows this statement. Higher market efficiency is shown to be achieved with the price setting. In addition, although the price is set for the wholesale electricity market in [6], time-based rates in retail markets can be set following a same process and readjusted due to the cost reflection of retail price from wholesale price in energy markets [5], [7] and [10].

Given the obtained optimal time horizon $T$, the time-based rates' pricing is set according to the following process:
The system operator starts a forward market energy auction of transaction periods $T$, in which all generators and retailers are required to submit their bids before a deadline. The bids of retailers take the form as:

$B=<P_{t}^{r e f}, p_{t}^{r e f}, \varepsilon_{T \times T} \mid t \in T>$

where $P_{t}^{r e f}$ is the reference consumption active power of retailers at hour $t(\mathrm{MW})$, and $p_{t}^{\text {ref }}$ reference selling price of the retailer at hour $t(\$ / \mathrm{MW} \cdot \mathrm{h})$. The reference price $p_{t}^{r e f}$ and demand $P_{t}^{r e f}$ should be a point on the retailer's end-user demand curve. $\varepsilon_{T \times T}$ is a $T \times T$ Price Elasticity Matrix (PEM) describing the customers' scheduling behaviors under the retailer. The concept is first proposed by [26] and [27]. Each entry of the PEM defines the change in electricity consumption at a scheduled hour $t$ due to a change in the electricity price of that same hour $t$ or any other hour $\tau$, and is expressed as

$\epsilon_{t \tau}=\frac{P_{t}-P_{t, r e f}}{p_{\tau}-p_{\tau, r e f}}=\frac{\Delta P_{t}}{\Delta p_{\tau}}$

Bidding profile (12) allows retailers' bids to describe their customers' inter-temporal constraints in a compact and straightforward manner with PEM.

Then the pricing is calculated by an iterative market clearing algorithm that is first proposed by [26] and [27], and improved by [6]. The algorithm is illustrated in Fig. 5 .

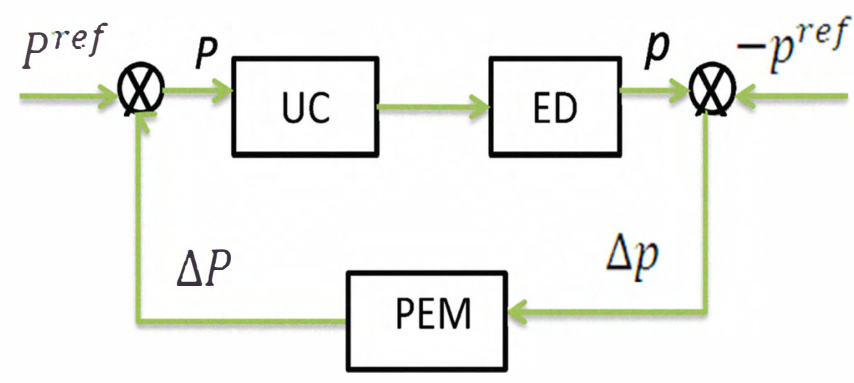

Fig. 5. The market interaction algorithm. In the figure, the UC and ED blocks refer to the unit commitment and economic dispatch. $D$ and $p$ are the demand and price. $D_{\text {ref }}$ and $p_{\text {ref }}$ are the reference points of demand and price. $\Delta D$ and $\Delta p$ are the deviation of demand and price from their reference points.

The algorithm's general idea can be described by its iterations: in the first iteration, the algorithm conducts demand-side-bundled unit commitment with the hourly demand as $P_{t}^{(0)}$ (which is denoted in retailers' bids as their reference load, $\left.P_{t}^{r e f}\right)$. The unit commitment gives the initial market clearing price as $p_{t}^{(0)}$. The algorithm compares $p_{t}^{(0)}$ with the reference price $p_{t}^{r e f}$ and calculates the difference, $\Delta p_{t}^{(0)}$. With $\Delta P^{0}=\varepsilon_{T \times T} \Delta p^{0}$, the algorithm determines the demand deviation $\Delta P_{t}^{(0)}$. The sum of $P_{t}^{r e f}$ and $\Delta P_{t}^{(0)}$ gives the end-user response to price $p_{t}^{0}$, which updates $P_{t}^{(0)}$ to $P_{t}^{(1)}$. The iterations are repeated until the condition $\left|P_{t}^{(K)}-P_{t}^{(K+1)}\right|<\xi$ 
is satisfied. $p_{t}^{K}$ for all the $t \in T$ will be the optimal pricing for time-based rates.

\section{CONCLUSION}

The application of Time-Based Rates (TBR) in modern power systems during the past several decades brings about more flexibility and options for both the supply and demand side, while it also increases the uncertainties in power system planning and operation. Therefore, it is important to create a TBR design approach that captures the benefit of flexibility, gets little induced uncertainties and thus reduces the system costs.

This paper presents a new two-step design approach of TBR programs. Conflicting interests from wind power prediction and customers' scheduling flexibility are considered in optimizing TBR's time horizon, in order to achieve a minimum system cost in forward and real-time reserve supplement energy market. The obtained time horizon is used as a known parameter in the subsequent design of TBR's pricing values. Customers' scheduling strategies modeled by price elasticity matrices along with current system conditions are considered in the price setting process, during which system cost of the forward energy market is minimized.

Future work includes testing the developed approach on specific power systems.

\section{REFERENCES}

[1] S. Borenstein, M. Jaske, and A. Rosenfeld, "Dynamic pricing, advanced metering and demand response in electricity markets," Center for the Study of Energy Markets, Oct. 31, 2002. [Online] Available: http://www.ucei.org

[2] "Benefits of demand response in electricity markets and recommendations for achieving them: a report to the United States Congress Pursuant to section 1252 of the Energy Policy Act of 2005." U.S. Department of Energy, 2006 [Online]. Available: http:// eetd.lbl.gov/ea/EMP/reports/congress-1252d.pdf

[3] FERC Staff, "Assessment of demand response and advanced metering," Federal Energy Regulatory Commission, Docket AD-06-2-000, Aug. 2006.

[4] R. B. Burke, M. I. Henderson, and S. E. Widergren, "A look ahead at demand response in New England," in Proc. PES General Meeting Conversion and Delivery of Electrical Energy in the $21^{\text {st }}$ Century, 2008 IEEE, pp. 1-6.

[5] S. D. Braithwait and K. Eakin, "The role of demand response in electric power market design." Laurits R. Christensen Associates, Inc., Madison, WI. [Online]. Available: http://www.eei.org

[6] J. Wang, "A demand responsive bidding mechanism with price elasticity matrix in wholesale electricity pools," MS. dissertation, Dept. Elect. Eng. \& Compt. Sci., MIT, Cambridge, MA, 2009.

[7] M. Fahrioglu and F. L. Alvarado, "The design of optimal demand management programs," in Proceedings of Bulk Power System Dynamics and Control IV-Restructuring, Santorini, Greece, Aug. 1998.

[8] M. H. Albadi and E. F. EI-Saadany, "Demand response in electricity markets: An overview," in Proc. PES General Meeting, 2007 IEEE, pp. $1-5$.

[9] C. L. Su and D. Kirschen, "Direct participation of demand-side in a pool-based electricity market," Power System Technology, vol. 31, no. 20, pp. 7-14, Oct. 2007.

[10] P. Cramton, "Electricity market design: The good, the bad, and the ugly," in Proc. Hawaii Int. Conf. System Sciences 2003 [Online]. Available: http://www.hicss.hawaii.edu/HICSS36/HICSSpapers/CSMAR08.pdf

[11] A. Fabbri, T. Gomez San Roman, J. Rivier Abbad, and V. H. M. Quezada, "Assessment of the cost associated with wind generation prediction errors in a liberalized electricity market," IEEE Trans. Power Syst., vol. 20, no. 3, pp. 1440-1446, Aug. 2005.
[12] E. D. Castronuovo and J. A. Pecas-Lopes, "On the optimization of the daily operation of a wind-hydro power plant," IEEE Trans. Power Syst., vol. 19, no. 3, pp. 1599-1606, Aug. 2004

[13] G. Giebel, G. Karinniotakis, and R. Brownsword, "The state-of-art in short-term prediction of wind power- a literuature overview. " Position paper for the ANEMOS project. [Online] Available: http://anemos.cma.fr

[14] H. Madsen, G. Kariniotakis, H. Nielsen, and P. Pinson, "A protocol for standardizing the performance evaluation of short-term wind power prediction models," in Proc. of yhr Global Wind Power 2004 Conf.

[15] H. Holttinen, P. Saarikivi, S. Repo, J. Ikaheimo, and G. Koreneff, "Prediction errors and balancing costs for wind power production in Finland", presented at the Global Wind Power Conference, Adelaide, 2006.

[16] U. Focken, M. Lange, K. Mönnich, H. P. Waldl, H. G. Beyer, and A. Luig, "Short-term prediction of the aggregated power output of wind farms-A statistical analysis of the reduction of the wind power prediction error by spatial smoothing effects," J. Wind Eng. Ind. Aerodyn., vol. 90, no. 3, pp. 231-246, 2002.

[17] S. Bofinger, A. Luig, and H. G. Beyer, "Qualification of wind power forecasts," in Proc. Global Wind Power Conf., Paris, France, Apr. 2-5, 2002.

[18] M. Milligan, M. Schwartz, and Y. Wan, "Statistical wind power forecasting models: Results for U.S. wind farms," in Proc. Windpower, Austin, TX, May 18-21, 2003, NREL/CP-500-33 956 Rep.

[19] P. Pinson and G. N. Kariniotakis, "Wind power forecasting using fuzzy neural networks enhanced with on-line prediction risk assessment," in Proc. 2003 IEEE Bologna Power Tech. Conf., Bologna, Italy, June.

[20] H. Brand, R. Barth, C. Weber, P. Meibom, D.J. Swider, "Extensions of wind power - effects on markets and costs of integration," in Proc. 2005 4. Internationale Energiewirtschaftstagung, Vien

[21] P. Meibom, C. Weber, R. Barth, and H. Brand, "Operational costs induced by fluctuating wind power production in Germany and Scandinavia", pp 133-154, In: Swider, D., Voss, A. (Eds), Deliverable D5b. GreenNet-EU27, 2006. [online] Available: http://greennet.igeneration.at

[22] H. Zeineldin, T. EI-Fouly, E. EI-Saadany, and M. Salama, "Impact of wind farm integration on electricity market prices," IET Renew. Power Gener., vol. 3, no. 1, pp. 84-95, 2009

[23] A. Moholkar, P. Klinkhachorn, and A. Feliachi, "Effects of dynamic pricing on residential electricity bill." Power Systems, IEEE Transactions on vol.2, pp. 1030-1035, 2004

[24] M. H. Nehrir, B. J. LaMeres, and V. Gerez, "A customer-interactive electric water heater demand-side management strategy using fuzzy logic," in Proc. IEEE Power Engineering Soc.Winter Meeting, vol. 2, Jan.-Feb. 1999, pp. 433-436.

[25] K. Bhattacharyya and M. Crow, "A fuzzy logic based approach to direct load control," IEEE Trans. on Power Systs, vol. 11, 2, May 1996, pp. 708-714

[26] D. S. Kirschen, G. Strbac, P. Cumperayot, and D. P. Mendes, "Factoring the elasticity of demand in electricity prices," IEEE Trans. Power Syst., vol. 15, pp. 612-617, May 2000

[27] A. K. David and Y. Z. Li, "Consumer rationality assumptions in the realtime pricing of electricity," IEE Proceedings, pt. C, vol. 139, no. 4, pp. 315-322, July 1992.

[28] F. Schweppe, B. Daryanian, and R. Tabors, "Algorithms for a spot price responding residential load controller," IEEE Trans Power Syst., vol. 4, no. 2, May 1989 , pp. 507-516

[29] W. Davis, T. Krapa, and M. Diedzic, "The economics of direct control of residential loads on the design and operation of the distribution system," IEEE Trans Power Syst, vol. PAS-102, no. 3, Mar. 1983, pp. 654-665.

[30] K. Ng and G. Sheble, "Direct load control- a profit-based load management using linear programming," IEEE Trans Power Syst, vol. 13 , no. 2 , May 1998 , pp. $688-695$. 


\section{BIOGRAPHIES}

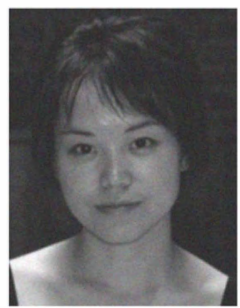

Jiankang Wang (S' 2008) became a student member of IEEE in 2008. She received a S.M. in EECS from MIT, Cambridge, MA in 2009.

Currently, she is a $\mathrm{PhD}$ student at MIT. Her research interests include electricity market analysis and design with demand response, and energy efficiency of smart grid.

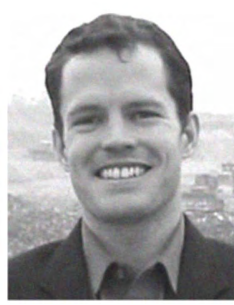

Scott W. Kennedy (M'2008) became a Member of IEEE in 2008. He received a $\mathrm{PhD}$ in Engineering Sciences and an S.M in Applied Math from Harvard University, Cambridge, MA in 2003.

$\mathrm{He}$ is an Associate Professor at the Masdar Institute of Science and Technology in Abu Dhabi, UAE. His current research interests include the integration of renewable energy sources into power networks, with an emphasis on the interactions between power markets and power system operations.

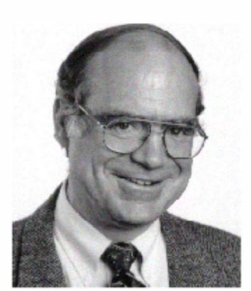

James L. Kirtley Jr. (S'69-M'71-SM'80-F'91) Received the S.B. and S.M degrees in 1968, EE in 1969 and Ph.D. in 1971 from MIT, all in Electrical Engineering.

$\mathrm{He}$ has been with the Massachusetts Institute of Technology as a member of the faculty since 1971, now serving as Professor of Electrical Engineering. He has also worked for General Electric Company as Engineer, Satcon Technology Corporation as Vice President, General Manager and Chief Scientist, and the Swiss Federal Institute of Technology as Gastdozent.

Dr. Kirtley has served as Editor in Chief of the IEEE Transactions on Energy Conversion and is on the editorial board of Electric Power Components and Systems. He is a member of the National Academy of Engineering and received the IEEE Third Millenium Medal in 2000 and the Nikola Tesla award in 2002. $\mathrm{He}$ is a registered professional engineer in Massachusetts. 